\title{
Macrophage activation marker SCD163 correlates with accelerated lipolysis following LPS exposure: a human-randomised clinical trial
}

\author{
Nikolaj Rittig', Mads Svart', Niels Jessen'ㄹ, Niels Møller ${ }^{1}$, Holger J Møller ${ }^{3}$ and Henning Grønbæk ${ }^{4}$ \\ 1Department of Internal Medicine and Endocrinology (MEA) and Medical Research Laboratory, Aarhus University Hospital, Aarhus C, Denmark \\ ${ }^{2}$ Research Laboratory for Biochemical Pathology, Institute for Clinical Medicine, Aarhus University Hospital, Aarhus C, Denmark \\ ${ }^{3}$ Department of Clinical Biochemistry Aarhus University Hospital, Aarhus C, Denmark \\ ${ }^{4}$ Department of Hepatology and Gastroenterology, Aarhus University Hospital, Aarhus C, Denmark
}

Correspondence should be addressed to N Rittig: nikolaj.rittig@clin.au.dk

\begin{abstract}
Background: Macrophage activation determined by levels of soluble SCD163 is associated with obesity, insulin resistance, diabetes mellitus type 2 (DM2) and non-alcoholic fatty liver disease (NAFLD). This suggests that macrophage activation is involved in the pathogenesis of conditions is characterised by adaptions in the lipid metabolism. Since sCD163 is shed to serum by inflammatory signals including lipopolysaccharides (LPS, endotoxin), we investigated SCD163 and correlations with lipid metabolism following LPS exposure.

Methods: Eight healthy male subjects were investigated on two separate occasions: (i) following an LPS exposure and (ii) following saline exposure. Each study day consisted of a four-hour non-insulin-stimulated period followed by a two-hour hyperinsulinemic euglycemic clamp period. A ${ }^{3} \mathrm{H}$-palmitate tracer was used to calculate the rate of appearance $\left(\mathrm{Ra}_{\text {palmitate }}\right)$. Blood samples were consecutively obtained throughout each study day. Abdominal subcutaneous adipose tissue was obtained for western blotting. Results: We observed a significant two-fold increase in plasma SCD163 levels following LPS exposure $(P<0.001)$, and SCD163 concentrations correlated positively with the plasma concentration of free fatty acids, $\mathrm{Ra}_{\text {palmitate }}$ lipid oxidation rates and phosphorylation of the hormone-sensitive lipase at serine 660 in adipose tissue $(P<0.05$, all). Furthermore, SCD163 concentrations correlated positively with plasma concentrations of cortisol, glucagon, tumour necrosis factor (TNF)- $\alpha$, interleukin (IL)-6 and IL-10 $(P<0.05$, all). Conclusion: We observed a strong correlation between SCD163 and stimulation of lipolysis and fat oxidation following LPS exposure. These findings support preexisting theory that inflammation and macrophage activation play a significant role in lipid metabolic adaptions under conditions such as obesity, DM2 and NAFLD.
\end{abstract}

\author{
Key Words \\ - sCD163 \\ - endotoxin/LPS \\ - lipid metabolism \\ - insulin resistance \\ - inflammation
}

\section{Introduction}

Macrophage activation is considered an important part of the pathogenesis of several diseases. Hence, the macrophage activation marker-soluble CD163 (sCD163) is of high interest and has already been associated with diseases such as obesity, sepsis, insulin resistance, diabetes mellitus type 2 (DM2) and non-alcoholic fatty liver disease (NAFLD) $(1,2,3,4,5,6)$. These diseases are also associated with changes in the lipid metabolism, accelerated lipolysis and increased circulating free fatty acid (FFA) levels $(7,8,9)$.
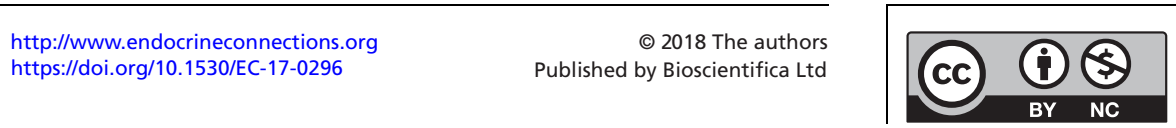

This work is licensed under a Creative Commons Attribution-NonCommercial 4.0 International License. 
Administration of LPS to healthy human volunteers is a well-established model simulating the initial steps of sepsis (10). The model excels itself by producing a homogeneous and uniform inflammatory response, which is attractive in clinical studies as it reduces interindividual differences and ensures a uniform inflammatory response in the hours following LPS. The LPS molecule is the major virulence factor of Gram-negative bacteria and binds to trans-membrane receptors named Toll-like receptors (TLR), which are expressed on the surface of innate immune cells (e.g. macrophages). Attachment of LPS to the TLR initiates intracellular signalling cascades that ultimately lead to the transcription and release of a broad range of pro- and anti-inflammatory cytokines, e.g. TNF- $\alpha(11,12)$. Furthermore, the same mechanism leads to shedding of sCD163, which can be measured in the circulation as a robust marker of macrophage activation (13, 14). We have previously shown how lipopolysaccharide (LPS) infusion causes increased lipolysis rates and insulin resistance in humans $(15,16)$ and others have shown how LPS exposure causes elevated concentrations of sCD163 $(13,17)$. However, the association between lipolysis and sCD163 has not yet been investigated.

The regulation of lipolysis is complex and has been reviewed by others in detail $(18,19)$. Concisely, inflammatory cytokines (especially TNF- $\alpha$ ) and hormones (especially epinephrine) stimulate lipolysis through the actions of adipose triglyceride lipase and hormonesensitive lipase (HSL), which are rate-limiting enzymes in the conversion of triglycerides into glycerol and FFA. Increased rates of lipolysis elevate circulating FFA concentrations and stimulate ketogenesis in the liver, and conversion of excessive FFA into ketone bodies, e.g. $\beta$-hydroxybutyrate (BHB) (20). The association between sCD163 and lipid metabolic adaptions is elusive.

The primary aim of this study was to confirm that LPS causes an increase in plasma sCD163 and to investigate if the increase in plasma sCD163 correlates with increased lipid metabolism, inflammatory cytokines and hormones following LPS exposure. We hypothesised that macrophage activation measured by sCD163 is involved in lipid metabolism and insulin resistance after LPS exposure.

\section{Materials and methods}

\section{Subjects and design}

Data originate from a human-randomised controlled crossover study from which results regarding protein and lipid metabolism have been published $(15,16)$. The study

$$
\begin{array}{lr}
\text { http://www.endocrineconnections.org } & \text { ○ } 2018 \text { The authors } \\
\text { https://doi.org/10.1530/EC-17-0296 } & \text { Published by Bioscientifica Ltd }
\end{array}
$$

design included eight healthy lean male test subjects who underwent three experimental interventions:

1. Saline (placebo).

2. LPS administration (LPS).

3. LPS and amino acid administration $(\mathrm{LPS}+\mathrm{A})$.

In this paper, we only present data from study arms (i) and (ii) because amino acid supplementation is beyond the scope of this paper.

The primary investigator enrolled all test subjects using a computerised programme to randomise interventions. Four of the test subjects received LPS during their first trial followed by placebo during their second trial and the other four test subjects received placebo first followed by LPS. During each trial, intravenous catheters were inserted in both cubital veins and one in a dorsal hand vein in order to give intravenous infusions and collect blood samples. Study days were separated with at least three weeks. Both study days consisted of a four-hour non-insulin-stimulated period followed by a two-hour hyperinsulinemic euglycemic clamp period.

\section{Ethics}

The Danish Ethical Committee approved the study (1-10-71-410-12) and registered at clinicaltrials.gov (NCT01705782). Both written and oral consents were obtained before inclusion of subjects in the trial. The study was conducted in accordance with the principles stated in the Declaration of Helsinki.

\section{Lipopolysaccharide (LPS)}

During intervention (ii) a bolus ( $1 \mathrm{ng} / \mathrm{kg}$ or $10 \mathrm{U} / \mathrm{kg}$ ) of Escherichia coli endotoxin (10,000 USP Endotoxin, lot H0K354; The United States Pharmacopeial Convention, Inc., Rockville, Maryland) was given at time $=0 \mathrm{~min}$ and was followed by a $10-\mathrm{mL}$ saline infusion. During placebo conditions, a $10-\mathrm{mL}$ saline infusion was given at time $=0 \mathrm{~min}$. Test subjects were blinded but were able to distinguish trail days due to significant clinical symptoms following LPS exposure.

\section{Hyperinsulinemic euglycemic clamp}

Insulin was infused at a rate of $1.0 \mathrm{U} / \mathrm{kg} / \mathrm{min}$ during the insulin-stimulated period (time $=240-360 \mathrm{~min}$, Insulin Actrapid; Novo-Nordisk, Copenhagen, Denmark). Plasma glucose concentrations were measured with a 10-min interval and variable rates of $20 \%$ glucose infusion were used to clamp plasma glucose concentrations at $5 \mathrm{mmol} / \mathrm{L}$. The

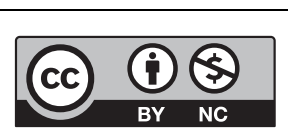

This work is licensed under a Creative Commons Attribution-NonCommercial 4.0 International License. 
glucose infusion rate (GIR) was then used as a measure of insulin sensitivity. Data are presented as the change in GIR between placebo and LPS conditions $\left(\Delta G I R=G_{\text {Pla- }}\right.$ cebo $-\mathrm{GIR}_{\mathrm{LPS}}$ ) to leave out inter-individual variability.

\section{Blood and tissue sample analysis}

Blood samples were stored at $-20^{\circ} \mathrm{C}$ and analysed in the same assay after all participants had completed all trials. Serum concentrations of cortisol (ELISA, DRG Cortisol Enzyme Immunoassay Kit, Germany), glucagon (EMD Millipore's Glucagon Radioimmunoassay (RIA) Kit), lactate and glucose (YSI 2300 model Stat Plus, Bie \& Berntsen), $\beta$-hydroxybutyrate (BHB) (hydrophilic interaction liquid chromatography tandem mass spectrometry (HILIC-MS/ MS)) and FFA (in vitro enzymatic colorimetric method assay NEFA-HR(2), Wako Chemicals GmbH, Germany) were analysed with the above standing methods and were all performed in accordance with the manufacturer's recommendations. Serum concentrations of tumour necrosis factor alpha (TNF- $\alpha$ ), interleukin (IL)- 6 and IL-10 were measured in a magnetic Bio-Plex Pro Human Chemokine Assay (Bio-Rad). sCD163 (BEP-2000 ELISA analyzer, Dade Behring, Marburg, Germany) was measured by an in-house assay essentially as previously described (21).

A continuous infusion of ${ }^{3} \mathrm{H}$-palmitate was used to determine the rate of appearance for palmitate $\left(\mathrm{Ra}_{\text {palmitate }}\right)$ at time $=240 \mathrm{~min}$. An abdominal subcutaneous adipose tissue (SAT) biopsy was obtained at time $=135 \mathrm{~min}$. Fat biopsies were successfully obtained and blotted for $n=7$. Western blot analysis was used to measure relative content and phosphorylation of relevant protein targets using the Bio-Rad Criterion system (Bio-Rad). Primary antibodies used were raised against phosphorylated $\left(\operatorname{ser}^{660}\right)$ and HSL (4107 and 4126 Cell Signaling).

\section{Indirect calorimetry}

An Oxycon Pro calorimeter (Intramedic, Gentofte, Denmark) with a canopy was applied at time $=180 \mathrm{~min}$. A 15-min period collection of respiratory gases was used to estimate resting energy expenditure and the respiratory quotient. Fat oxidation rates were calculated as previously described (22). Due to technical problems, calorimetry measurements were only performed in seven subjects.

\section{Statistics}

All statistical analyses and graphs were made using Stata 13 (College Station, Texas, USA) and SigmaPlot 11 (San

$$
\begin{aligned}
& \text { http://www.endocrineconnections.org } \\
& \text { https://doi.org/10.1530/EC-17-0296 }
\end{aligned}
$$

C) 2018 The authors Published by Bioscientifica Ltd
Jose, California, USA). Unequal distributed data were logarithmically converted. $P$-Values $<0.05$ were considered significant. Two-way repeated measure ANOVA was used to test for interactions in sCD163 concentrations during time in the study period and between groups. In the event of significant interaction, multiple pairwise comparisons were performed using the Student-Newman-Keuls method. Correlations between $\Delta \mathrm{GIR}$ and $\Delta$ sCD163 were evaluated using parametric linear regression. Correlations between sCD163 and other outcomes were evaluated using a mixed model linear regression adjusting for the crossover design and reuse of test subjects.

\section{Results}

Subjects

The test subjects had a median age of 26 years (range: 25-32), a median BMI of $23 \mathrm{~kg} / \mathrm{m}^{2}$ (range: $22-26$ ) and a median body weight of $79 \mathrm{~kg}$ (range $68-85 \mathrm{~kg}$ ) as reported previously (16).

\section{Concentrations of sCD163}

The mean concentration of sCD163 was comparable at baseline (placebo and LPS at time $=0 \mathrm{~min}, P=0.78$ ) but increased rapidly 2-3-fold and remained elevated throughout the study period during LPS conditions compared with placebo (Fig. 1, two-way repeated measure

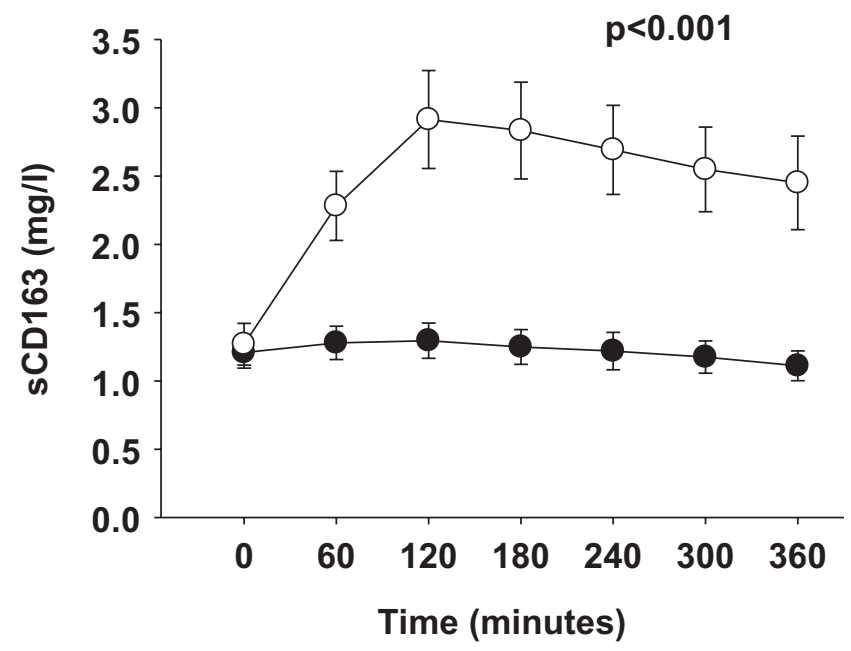

Figure 1

Plasma SCD163 concentrations. The mean plasma concentration ( \pm S.E.M.) of sCD163 during the study period is shown for placebo $(0)$ and LPS (O) conditions. Repeated measurement two-way ANOVA analysis was used to test for differences between groups. $N=8$.

This work is licensed under a Creative Commons Attribution-NonCommercial 4.0 International License. 

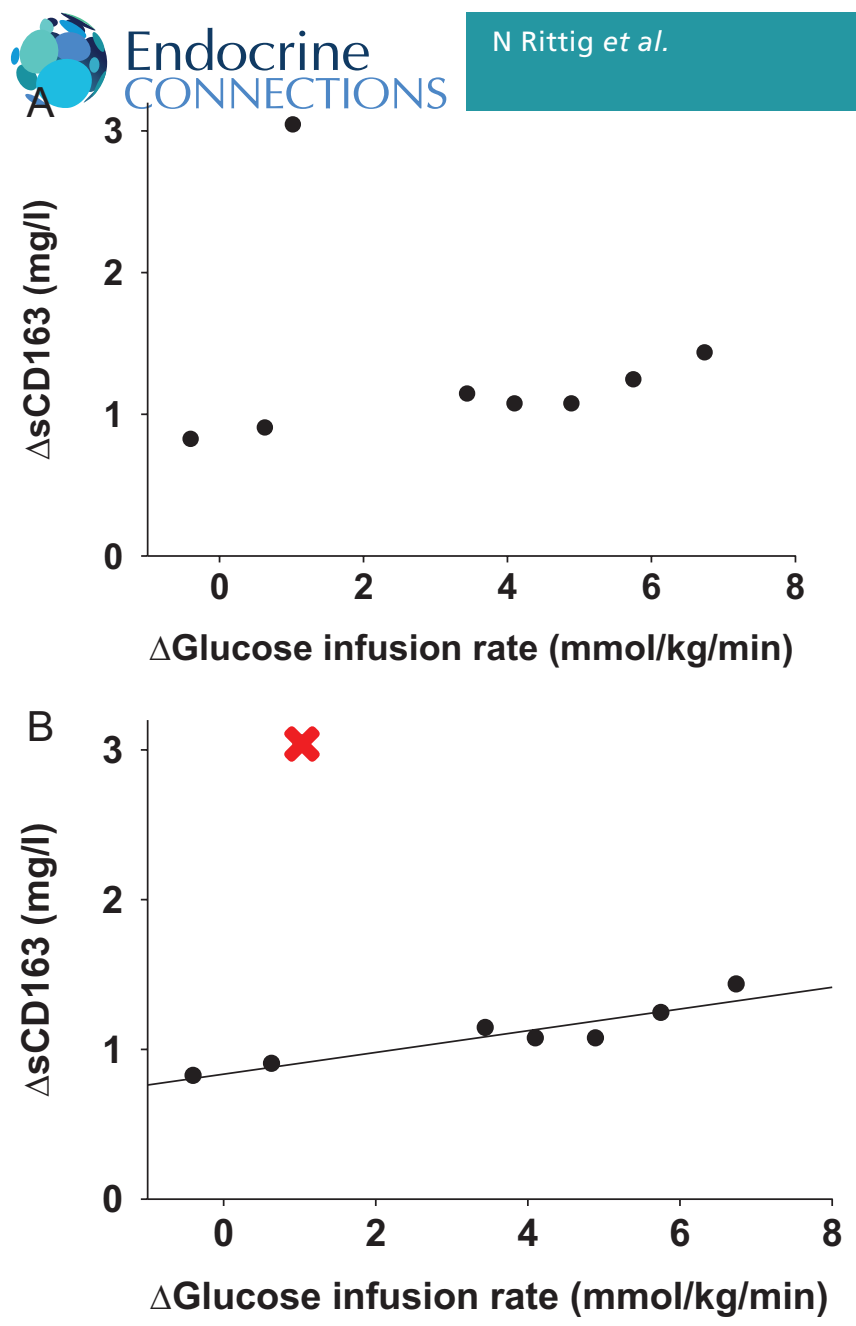

Figure 2

Insulin resistance and SCD163. The change in plasma concentrations of $s C D 163\left(\Delta S C D 163=s C D 163_{\text {LPS }}-s C D 163_{\text {placebo }}\right)$ and the change in glucose infusion rates during the hyperinsulinemic euglycemic clamp period $\left(\mathrm{GIR}, \Delta \mathrm{GIR}=\mathrm{GIR}_{\text {placebo }}-\mathrm{GIR}_{\mathrm{LPS}}\right)$ during $\mathrm{LPS}$ and placebo exposures are shown for the eight test subjects (A). A parametric linear regression analysis showed no significant correlation between $\triangle \mathrm{SCD} 163$ and $\triangle \mathrm{GIR}$ $(P=0.8) . N=8$. When excluding the outlier (marked with a red cross), parametric linear regression showed a significant $\left(P<0.001, r^{2}=0.87\right)$ positive correlation between $\triangle \mathrm{GIR}$ (insulin resistance) and $\triangle \mathrm{SCD} 163$ (B). $N=7$.

ANOVA interaction $P<0.001)$. One of the test subjects developed markedly higher concentrations of sCD163 $(\approx 4$-fold increase) during time $=60-360 \mathrm{~min}$ compared with the other seven test subjects ( $\approx 2$-fold increase) under LPS conditions. All test subjects had roughly the same plasma concentration of sCD163 during placebo conditions $(\approx 1.2 \mathrm{mg} / \mathrm{L})$.

\section{Insulin resistance}

We used the hyperinsulinaemic euglycaemic clamp technique to obtain GIR values during both placebo and LPS conditions. There was no significant correlation between the increase in sCD163 concentrations $\left(\Delta \mathrm{sCD} 163=\mathrm{sCD} 163_{\mathrm{LPS}}-\mathrm{sCD} 163_{\text {placebo }}\right)$ and the increase in insulin resistance $\left(\Delta \mathrm{GIR}=\mathrm{GIR}_{\text {placebo }}-\mathrm{GIR}_{\mathrm{LPS}}\right)$ during $\mathrm{LPS}$ conditions compared with placebo (Fig. 2A). However, when excluding the abovementioned outlier, there was a significant (simple linear regression $P<0.001$ ) positive correlation between $\Delta$ sCD163 and $\Delta$ GIR (Fig. 2B).

\section{Lipid metabolism}

There was a significant positive correlation between plasma concentrations of FFA $(P<0.005)$, lipid oxidation rates $(P=0.007), \mathrm{Ra}_{\text {palmitate }}(P<0.005)$ and plasma concentrations of $\mathrm{BHB}(P=0.006)$ with the plasma concentrations of sCD163 at time $\approx 240 \mathrm{~min}$ (Fig. 3 and Table 1 ). Additionally, sCD163 concentrations also had a significant $(P<0.005)$ positive correlation with the phosphorylated amount of HSL (involved in lipolysis) in SAT biopsies (Fig. 3).

\section{Inflammation}

The peak increments in plasma cortisol, glucagon, IL-6, IL-10 and TNF- $\alpha$ all had a significant (all, $P<0.005$ ) positive
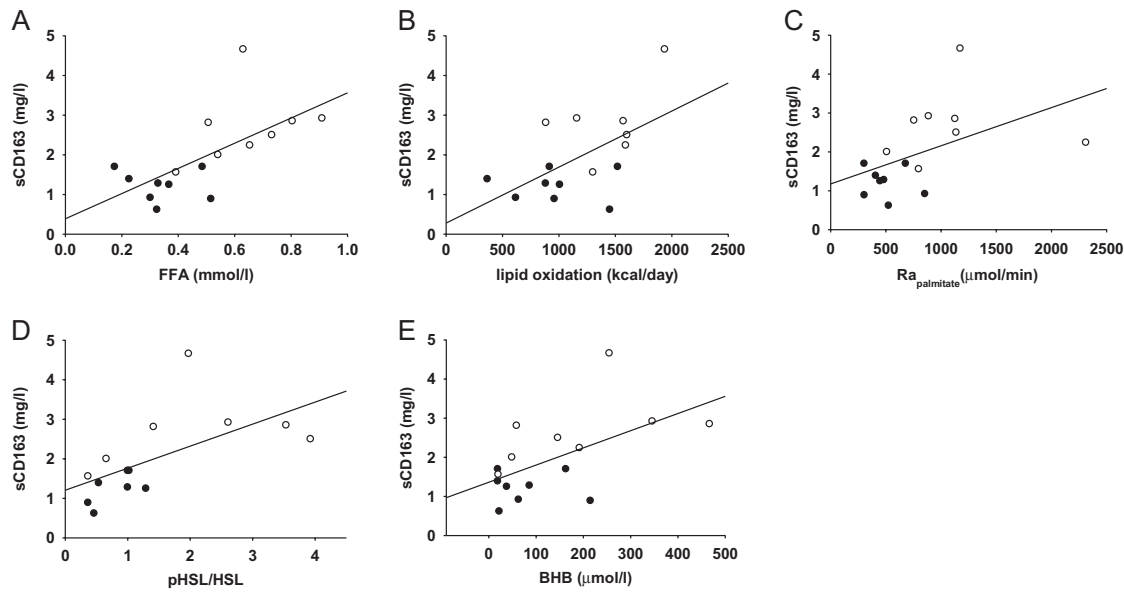

http://www.endocrineconnections.org https://doi.org/10.1530/EC-17-0296

(C) 2018 The author Published by Bioscientifica Ltd
Figure 3

Lipid metabolism and SCD163. Data are presented as dot plots showing (A) plasma concentrations of free fatty acids (FFAs), (B) lipid oxidation rates, (C) rate of appearance for palmitat $\left(\mathrm{Ra}_{\text {palmitat }}\right)$, (D) ratio of phosphorylated hormone-sensitive lipase at ser ${ }^{660}(\mathrm{HSL})$ to content of HSL (pHSL/HSL) and (E) plasma concentrations of $\beta$-hydroxybutyrate (BHB) on the horizontal axis and concentrations of sCD163 on the vertical axis following exposure to placebo $(\bullet)$ and LPS $(0)$. All measurements were performed around time $=240 \mathrm{~min}$ (at the end of the non-insulin-stimulated period of the trial day). A mixed model linear regression analysis was used to test for correlations. $N=8$ in graphs (A), (C) and (E). N=7 in graphs (B) and (D). 
Table 1 Correlations between SCD163 and metabolic and inflammatory parameters.

\begin{tabular}{|c|c|c|c|}
\hline sCD163 & $\beta$-Coefficient & $95 \% \mathrm{Cl}$ & P-Value \\
\hline \multicolumn{4}{|l|}{ Metabolism } \\
\hline FFA (mmol/L) & 3.2 & $1.5 ; 4.9$ & $<0.005$ \\
\hline $\begin{array}{l}\text { Lipid oxidation } \\
\text { (kcal/day) }\end{array}$ & 0.001 & $0.0004 ; 0.002$ & 0.007 \\
\hline $\mathrm{Ra}_{\text {palmitate }}(\mu \mathrm{mol} / \mathrm{min})$ & 3.3 & $1.8 ; 4.8$ & $<0.005$ \\
\hline $\mathrm{pHSL/HSL}$ & 0.6 & $0.2 ; 0.9$ & $<0.005$ \\
\hline $\mathrm{BHB}(\mathrm{mmol} / \mathrm{L})$ & 0.004 & $0.001 ; 0.008$ & 0.006 \\
\hline \multicolumn{4}{|l|}{ Inflammation } \\
\hline IL-6 (ng/mL) & 0.0008 & $0.0006 ; 0.001$ & $<0.005$ \\
\hline IL-10 (ng/mL) & 0.01 & $0.005 ; 0.02$ & $<0.005$ \\
\hline TNF- $\alpha(\mathrm{ng} / \mathrm{mL})$ & 0.003 & $0.003 ; 0.003$ & $<0.005$ \\
\hline Glucagon $(\mu \mathrm{g} / \mathrm{L})$ & 0.02 & $0.01 ; 0.03$ & $<0.005$ \\
\hline Cortisol $(\mu \mathrm{g} / \mathrm{mL})$ & 0.008 & $0.006 ; 0.010$ & $<0.005$ \\
\hline Heart rate (beats/min) & 0.05 & $0.03 ; 0.06$ & $<0.005$ \\
\hline Temperature $\left({ }^{\circ} \mathrm{C}\right)$ & 0.6 & $0.4 ; 0.8$ & $<0.005$ \\
\hline
\end{tabular}

Correlations were evaluated using a mixed model linear regression. The $\beta$-coefficient, $95 \%$ confidence interval $(95 \% \mathrm{Cl})$ and $P$-value of the tests are shown.

BHB, $\beta$-hydroxybutyrate; FFA, free fatty acids; HSL, hormone-sensitive lipase; IL, interleukine; Ra, rate of appearance; TNF, tumour necrotic factor.

correlation with the peak increment of sCD163 (Fig. 4 and Table 1). Additionally, the peak in body temperature and heart rate also correlated significantly (both, $P<0.005$ ) with the peak concentration of sCD163 (Table 1).

\section{Discussion}

Here, we demonstrate how sCD163 concentrations increased during the hours following LPS exposure. As novel findings, we show significant positive correlations between sCD163 and insulin resistance, different key factors in lipid metabolism, pro-inflammatory cytokines and inflammatory hormones. These findings bring new insight and understanding to the field of research concerning obesity, insulin resistance, DM2 and NAFLD and suggest macrophages to play an important role.

Exposure to LPS rapidly increased sCD163 concentrations, which remained elevated for the six-hour trial period, as reported in previous studies investigating sCD163 following LPS administration (13, 17). These studies reported slightly higher concentrations of both sCD163 $(\approx 5 \mathrm{mg} / \mathrm{L}$ vs $\approx 2 \mathrm{mg} / \mathrm{L}$ in our study) and TNF- $\alpha$ $(\approx 700 \mathrm{pg} / \mathrm{mL}$ vs $\approx 400 \mathrm{pg} / \mathrm{mL}$ in our study). Most likely, this difference is due to the higher doses of LPS given in these studies $(4 \mathrm{ng} / \mathrm{kg})$ compared with the dose given in our study ( $1 \mathrm{ng} / \mathrm{kg})$.

The sCD163 has already been associated with insulin resistance, obesity and DM2 (3, 23, 24). Studies investigating sCD163 and insulin resistance have primarily used the HOMA index to quantify insulin resistance, while only few have used the hyperinsulinemic euglycemic clamp technique (25), which is considered the gold standard method to measure insulin resistance. We used the hyperinsulinemic euglycemic clamp and found a significant positive correlation between the change in sCD163 and the change in insulin resistance (change in GIR $=\Delta$ GIR) when excluding the outlier from our data. These findings are in accordance with the abovementioned studies, but notably these studies were cross-sectional observational studies investigating obese, prediabetic and DM2 patients. In contrast, we applied a randomised crossover design and explored the acute changes in sCD163 and insulin resistance, thereby excluding possible inter-individual confounding.

We extensively investigated lipid metabolism using palmitate tracer technique, indirect calorimetry, SAT biopsies and blood sample collection during both placebo and LPS exposures demonstrating how concentrations
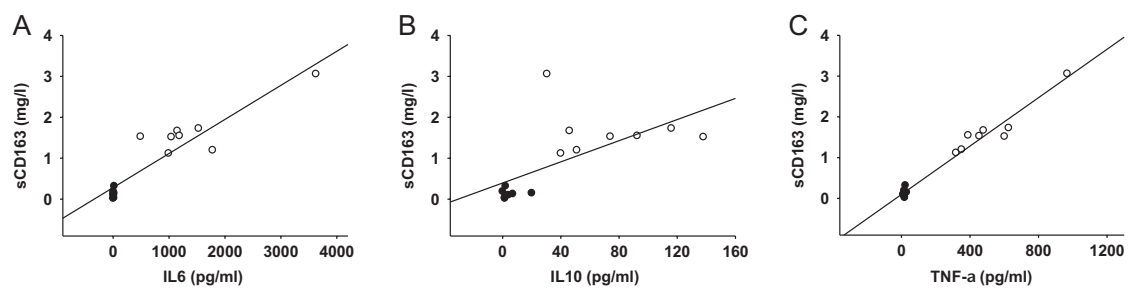

\section{Figure 4}

Inflammatory cytokines/hormones and SCD163. Data are presented as dot plots showing peak plasma concentrations of (A) interleukin (IL)-6, (B) IL-10, (C) tumour necrotic factor (TNF)- $\alpha$, (D) cortisol and (E) glucagon on the horizontal axis and peak plasma concentrations of SCD163 on the vertical axis following exposure to placebo (0) and LPS (O). $N=8$ in all graphs. A mixed model linear regression analysis was used to test for correlations.

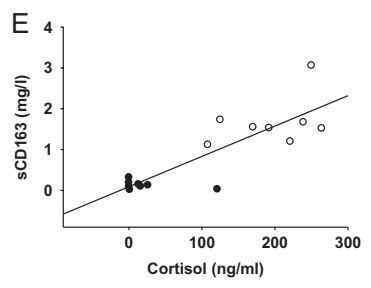

http://www.endocrineconnections.org https://doi.org/10.1530/EC-17-0296

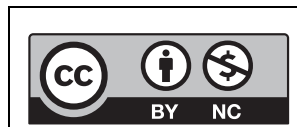

This work is licensed under a Creative Commons Attribution-NonCommercial 4.0 International License. 
of sCD163 were positively correlated with accelerated lipolysis, increased plasma FFA, lipid oxidation, $\mathrm{Ra}_{\text {palmitate }}$ and phosphorylation of HSL in SAT biopsies. The increased circulating FFA may result in adipose tissue insulin resistance with ectopic lipid deposition, which has been proposed to precede insulin resistance in muscle and liver $(26,27,28)$. Ultimately, elevated circulating FFAs are beta-oxidised in the liver resulting in increased concentrations of ketone bodies, e.g. BHB. Here, we demonstrated how plasma concentration of sCD163 correlated positively with plasma concentrations of $\mathrm{BHB}$ $(P<0.005)$ in agreement with the elevated circulating levels of FFA providing increased substrate supply to the liver.

We used a human model simulating the initial stage of sepsis in healthy lean subjects. Albeit these subjects were not suffering from obesity, DM2 and NAFLD, the model inducted metabolic adaptions characterising these conditions: insulin resistance and increased lipolysis. Thus, conditions such as obesity, DM2 and NAFLD are all characterised by chronic low-grade inflammation; on the other hand, we investigated an acute and more pronounced inflammatory condition. It is well known that the release of cytokines following LPS exposure is dynamic and changes during time (10). Furthermore, intracellular signals involved in the regulation of lipolysis also change during time $(18,19)$. Extrapolations should therefore be done with caution. Despite these facts, our results indicate that sCD163 and thereby macrophage activation may play an important role in the adaptions occurring in lipid and glucose metabolism during the acute phase of inflammation.

The increment in sCD163 levels following LPS exposure was highly correlated with TNF- $\alpha$, which is in line with preexisting literature indicating that TNF$\alpha$ and sCD163 are released by ectodomain shedding following LPS attachment to the TLR-4 and subsequently activation of the TNF- $\alpha$ converting enzyme (TACE/ ADAM17) in macrophages $(13,17,29)$. Even though several studies have already shown that the shedding of sCD163 can be induced by LPS (17), PMA (phorbol 12-myristate 13-acetat) (30), oxidative stress (31) and thrombin (32), most of these are in vitro studies using monocyte/macrophage cell cultures with only sparse human in vivo studies investigating sCD163 preceding LPS (17). Decisively, sCD163 increases rapidly and in close alignment with TNF- $\alpha$, but the exact function of sCD163 remains elusive. In addition to $\mathrm{TNF}-\alpha$, we also found other inflammatory parameters such as IL-6, IL-10, cortisol, glucagon, body temperature and heart rate that correlated positively with sCD163 concentrations $(P<0.05)$. All these abovementioned inflammatory parameters peaked in alignment with sCD163 concentrations within the first $3 \mathrm{~h}$ preceding LPS exposure (data not shown), emphasising sCD163 as an inflammatory biomarker.

Strengths of the study include the randomised controlled crossover design and use of human test subjects especially considering the fact that the majority of studies investigating sCD163 apply an observational crosssectional or in vitro design. Additionally, we thoroughly investigated metabolic adaptions using ${ }^{3} \mathrm{H}$-palmitate tracer technique, hyperinsulinemic euglycemic clamp, indirect calorimetry and western blotting of SAT biopsies. Our study is limited by the use of only eight healthy, lean, male test subjects and the use of a disease model. Therefore, extrapolation of results to clinical conditions should be done with caution.

In conclusion, LPS exposure elevates plasma sCD163 concentrations, which was positively correlated with insulin resistance, key elements of lipid metabolism and inflammatory cytokines (e.g. TNF- $\alpha$ ). These novel findings support preexisting theory that inflammation and macrophage activation play a vital role in lipid metabolic adaptions during conditions such as obesity, sepsis, DM2 and NAFLD.

\section{Declaration of interest}

The authors declare that there is no conflict of interest that could be perceived as prejudicing the impartiality of the research reported.

\section{Funding}

This work was financially supported by Aarhus University (Denmark), the Danish Council for Strategic Research (grant no. 0603-00479B), the Danish Strategic Research Council (10-092797) and the Lundbeck foundation (R83-A8172). HG received funding from the Novo-Nordisk Foundation and 'Savværksejer Jeppe Juhl og hustru Ovita Juhls mindelegat'.

\section{Acknowledgements}

The authors would like to thank Annette Mengel, Lisa Buus and Helle Hauser Ryom for their outstanding work and support during the whole study. Furthermore, the authors would also like to thank the eight test subjects for participating in their trial. N R is the guarantor of the article and thereby takes responsibility for the work as a whole and the inception to the published article. $\mathrm{N} \mathrm{R}$ performed the research. N R, H J and $\mathrm{N} \mathrm{J}$ analysed and collected the data. N R, M S, N M, N J and H G all contributed to the design of the study. N R and H G wrote the article. All authors read and approved the final manuscript. 


\section{References}

1 Fjeldborg K, Pedersen SB, Moller HJ, Rask P, Danielsen AV, StødkildeJørgensen H \& Richelsen B. Intrahepatic fat content correlates with soluble CD163 in relation to weight loss induced by Roux-en-Y gastric bypass. Obesity 201523 154-161. (https://doi.org/10.1002/ oby.20942)

2 Parkner T, Sorensen LP, Nielsen AR, Fischer CP, Bibby BM, Nielsen S, Pedersen BK \& Møller HJ. Soluble CD163: a biomarker linking macrophages and insulin resistance. Diabetologia 201255 1856-1862. (https://doi.org/10.1007/s00125-012-2533-1)

3 Sorensen LP, Parkner T, Sondergaard E, Bibby BM, Moller HJ \& Nielsen S. Visceral obesity is associated with increased soluble CD163 concentration in men with type 2 diabetes mellitus. Endocrine Connections 20154 27-36. (https://doi.org/10.1530/EC-14-0107)

4 Kazankov K, Barrera F, Moller HJ, Rosso C, Bugianesi E, David E, Ibrahim Kamal Jouness R, Esmaili S, Eslam M, McLeod D, et al. The macrophage activation marker sCD163 is associated with morphological disease stages in patients with non-alcoholic fatty liver disease. Liver International 201636 1549-1557. (https://doi. org/10.1111/liv.13150)

5 Kazankov K, Tordjman J, Moller HJ, Vilstrup H, Poitou C, Bedossa P, Bouillot JL, Clement K \& Grønbaek H. Macrophage activation marker soluble CD163 and non-alcoholic fatty liver disease in morbidly obese patients undergoing bariatric surgery. Journal of Gastroenterology and Hepatology 201530 1293-1300. (https://doi.org/10.1111/ jgh.12943)

6 Gaini S, Pedersen SS, Koldkaer OG, Pedersen C, Moestrup SK \& Møller HJ. New immunological serum markers in bacteraemia: anti-inflammatory soluble CD163, but not proinflammatory high mobility group-box 1 protein, is related to prognosis. Clinical and Experimental Immunology 2008151 423-431. (https://doi. org/10.1111/j.1365-2249.2007.03586.x)

7 Fabbrini E, Sullivan S \& Klein S. Obesity and nonalcoholic fatty liver disease: biochemical, metabolic, and clinical implications. Hepatology 201051 679-689. (https://doi.org/10.1002/hep.23280)

8 Groop LC, Bonadonna RC, DelPrato S, Ratheiser K, Zyck K, Ferrannini E \& DeFronzo RA. Glucose and free fatty acid metabolism in non-insulin-dependent diabetes mellitus. Evidence for multiple sites of insulin resistance. Journal of Clinical Investigation $1989 \mathbf{8 4}$ 205-213. (https://doi.org/10.1172/JCI114142)

9 Chambrier C, Laville M, Rhzioual Berrada K, Odeon M, Bouletreau P $\&$ Beylot M. Insulin sensitivity of glucose and fat metabolism in severe sepsis. Clinical Science 200099 321-328. (https://doi. org/10.1042/cs0990321)

10 Andreasen AS, Krabbe KS, Krogh-Madsen R, Taudorf S, Pedersen BK \& Møller K. Human endotoxemia as a model of systemic inflammation. Current Medicinal Chemistry 200815 1697-1705. (https://doi. org/10.2174/092986708784872393)

11 May MJ \& Ghosh S. Signal transduction through NF-kappa B. Immunology Today 199819 80-88. (https://doi.org/10.1016/S01675699(97)01197-3)

12 Fijen JW, Kobold AC, de Boer P, Jones CR, van der Werf TS, Tervaert JW, Zijlstra JG \& Tulleken JE. Leukocyte activation and cytokine production during experimental human endotoxemia. European Journal of Internal Medicine 200011 89-95. (https://doi. org/10.1016/S0953-6205(00)00068-6)

13 Etzerodt A, Maniecki MB, Moller K, Moller HJ \& Moestrup SK. Tumor necrosis factor alpha-converting enzyme (TACE/ADAM17) mediates ectodomain shedding of the scavenger receptor CD163. Journal of Leukocyte Biology 201088 1201-1205. (https://doi.org/10.1189/ jlb.0410235)

14 Etzerodt A, Rasmussen MR, Svendsen P, Chalaris A, Schwarz J, Galea I, Møller HJ \& Moestrup SK. Structural basis for inflammationdriven shedding of CD163 ectodomain and tumor necrosis factor-alpha in macrophages. Journal of Biological Chemistry 2014289 778-788. (https://doi.org/10.1074/jbc.M113.520213)

15 Rittig N, Bach E, Thomsen HH, Pedersen SB, Nielsen TS, Jørgensen JO, Jessen N \& Møller N. Regulation of lipolysis and adipose tissue signaling during acute endotoxin-induced inflammation: a human randomized crossover trial. PLOS ONE 2016 11 e0162167. (https://doi.org/10.1371/journal.pone.0162167) 16 Rittig N, Bach E, Thomsen HH, Johannsen M, Jorgensen JO, Richelsen B, Jessen N \& Møller N. Amino acid supplementation is anabolic during the acute phase of endotoxin-induced inflammation: a human randomized crossover trial. Clinical Nutrition 201535 322-330. (https://doi.org/10.1016/j.clnu.2015.03.021)

17 Hintz KA, Rassias AJ, Wardwell K, Moss ML, Morganelli PM, Pioli PA, Givan AL, Wallace PK, Yeager MP \& Guyre PM. Endotoxin induces rapid metalloproteinase-mediated shedding followed by up-regulation of the monocyte hemoglobin scavenger receptor CD163. Journal of Leukocyte Biology 200272 711-717.

18 Lass A, Zimmermann R, Oberer M \& Zechner R. Lipolysis - a highly regulated multi-enzyme complex mediates the catabolism of cellular fat stores. Progress in Lipid Research 201150 14-27. (https://doi. org/10.1016/j.plipres.2010.10.004)

19 Nielsen TS, Jessen N, Jorgensen JO, Moller N \& Lund S. Dissecting adipose tissue lipolysis: molecular regulation and implications for metabolic disease. Journal of Molecular Endocrinology 201452 R199-R222. (https://doi.org/10.1530/JME-13-0277)

20 Fukao T, Lopaschuk GD \& Mitchell GA. Pathways and control of ketone body metabolism: on the fringe of lipid biochemistry. Prostaglandins, Leukotrienes and Essential Fatty Acids 200470 243-251. (https://doi.org/10.1016/j.plefa.2003.11.001)

21 Moller HJ, Hald K \& Moestrup SK. Characterization of an enzymelinked immunosorbent assay for soluble CD163. Scandinavian Journal of Clinical and Laboratory Investigation 200262 293-299. (https://doi. org/10.1080/003655102760145852)

22 Ferrannini E. The theoretical bases of indirect calorimetry: a review. Metabolism 198837 287-301. (https://doi.org/10.1016/00260495(88)90110-2)

23 Reid M, Ma Y, Scherzer R, Price JC, French AL, Plankey MW Grunfeld C \& Tien PC. Higher CD163 levels are associated with insulin resistance in hepatitis $C$ virus-infected and HIVinfected adults. AIDS 201731 385-393. (https://doi.org/10.1097/ QAD.0000000000001345)

24 Deichgraeber P, Witte DR, Moller HJ, Skriver MV, Richelsen B, Jørgensen ME, Johansen NB \& Sandbæk A. Soluble CD163, adiponectin, C-reactive protein and progression of dysglycaemia in individuals at high risk of type 2 diabetes mellitus: the ADDITIONPRO cohort. Diabetologia 201659 2467-2476. (https://doi. org/10.1007/s00125-016-4075-4)

25 Kracmerova J, Rossmeislova L, Kovacova Z, Klimcakova E, Polak J, Tencerová M, Mališová L, Štich V, Langin D \& Šiklová M. Soluble CD163 is associated with CD163 mRNA expression in adipose tissue and with insulin sensitivity in steady-state condition but not in response to calorie restriction. Journal of Clinical Endocrinology and Metabolism 201499 E528-E535. (https://doi.org/10.1210/jc.20133348)

26 Ferrannini E, Barrett EJ, Bevilacqua S \& DeFronzo RA. Effect of fatty acids on glucose production and utilization in man. Journal of Clinical Investigation 198372 1737-1747. (https://doi.org/10.1172/ JCI111133)

27 Sondergaard E, Espinosa De Ycaza AE, Morgan-Bathke M \& Jensen MD. How to measure adipose tissue insulin sensitivity. Journal of Clinical Endocrinology and Metabolism 2017102 1193-1199. (https://doi.org/10.1210/jc.2017-00047)

28 Shulman GI. Ectopic fat in insulin resistance, dyslipidemia, and cardiometabolic disease. New England Journal of Medicine 2014371 2237-2238. (https://doi.org/10.1056/NEJMc1412427) http://www.endocrineconnections.org https://doi.org/10.1530/EC-17-0296
() 2018 The authors Published by Bioscientifica Ltd
This work is licensed under a Creative Commons Attribution-NonCommercial 4.0 International License. 
29 Le Gall SM, Maretzky T, Issuree PD, Niu XD, Reiss K, Saftig P, Khokha R, Lundell D \& Blobel CP. ADAM17 is regulated by a rapid and reversible mechanism that controls access to its catalytic site. Journal of Cell Science 2010123 3913-3922. (https://doi.org/10.1242/ jcs.069997)

30 Droste A, Sorg C \& Hogger P. Shedding of CD163, a novel regulatory mechanism for a member of the scavenger receptor cysteine-rich family. Biochemical and Biophysical Research Communications 1999256 110-113. (https://doi.org/10.1006/ bbrc.1999.0294)
31 Timmermann M \& Hogger P. Oxidative stress and 8-iso-prostaglandin $\mathrm{F}$ (2alpha) induce ectodomain shedding of CD163 and release of tumor necrosis factor-alpha from human monocytes. Free Radical Biology and Medicine 200539 98-107. (https://doi.org/10.1016/j. freeradbiomed.2005.02.031)

32 Chung S, Kim JE, Park S, Han KS \& Kim HK. Neutrophil and monocyte activation markers have prognostic impact in disseminated intravascular coagulation: in vitro effect of thrombin on monocyte CD163 shedding. Thrombosis Research $2011 \mathbf{1 2 7}$ 450-456. (https://doi.org/10.1016/j.thromres.2010.12.021)

Received in final form 22 November 2017

Accepted 27 November 2017 http://www.endocrineconnections.org https://doi.org/10.1530/EC-17-0296

(c) 2018 The authors Published by Bioscientifica Ltd

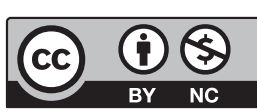

This work is licensed under a Creative Commons Attribution-NonCommercial 4.0 International License. 